\title{
Dovish and Hawkish Influence in Distributive and Integrative Negotiations: The Role of (A)symmetry in Constituencies
}

\author{
Hillie Aaldering ${ }^{1}\left[\right.$. Shirli Kopelman ${ }^{2}$
}

Accepted: 24 August 2021 / Published online: 7 September 2021

(c) The Author(s) 2021

\begin{abstract}
Dovish and hawkish constituency pressures influence representative negotiations. Dovish constituency voices promote a collaborative and problem-solving approach, but can also allow for exploitation in negotiations. Hawkish voices encourage a competitive approach, but may leave value on the table. These dynamics are investigated in four experiments. In two interactive dyadic-negotiation experiments (Experiments $1 \& 2 ; N=186$ and $N=220$ ), we investigated how constituency pressures influenced outcomes in two negotiation settings (distributive and integrative). Representatives of dovish constituencies reached higher negotiation outcomes than representatives of hawkish constituencies, when facing a representative with a similar constituency (Experiment 1). However, when representatives with a dovish constituency met with representatives of a hawkish constituency, dovish representatives reached lower gains in both negotiation settings (Experiment 2). This hawkish advantage was replicated in two online scenario studies (Experiments $3 \& 4 ; N=248$ and $N=319$ ). There was no consistent empirical support for the role of a potential future interaction in eliciting representatives' concessions (Experiment 1-3), however, an absence of accountability to constituents reduced representatives' competitiveness, irrespective of whom they represented (Experiment 4). Theoretical and practical implications for labor relations, diplomacy, and business negotiations are discussed.
\end{abstract}

Keywords Negotiation $\cdot$ Integrative $\cdot$ Distributive $\cdot$ Representative $\cdot$ Constituency

Hillie Aaldering

H.Aaldering@uva.nl

1 Department of Psychology, University of Amsterdam, Nieuwe Achtergracht 129B, 1018 WT Amsterdam, The Netherlands

2 Ross School of Business, University of Michigan, Ann Arbor, MI, USA 


\section{Introduction}

In inter- and intra-organizational negotiations parties are often represented by one or more individuals. Representatives face the challenging task to negotiate an acceptable agreement with their counterpart, while also satisfying the demands of their constituents. Indeed, representatives tend to negotiate in a more competitive way than non-representatives, due to experienced accountability pressures from their constituency (e.g. Benton and Druckman 1973; Ben-Yoav and Pruitt 1984a). Research has consistently shown the important influence of constituent voices on negotiation outcomes. When the constituency takes a hawkish stance, representatives may use more competitive tactics to secure high outcomes for their party (Steinel et al. 2009), but these may lead to suboptimal agreements, when the structure of the negotiation allows for mutually beneficial solutions for both parties (De Dreu et al. 2014). Alternatively, when constituents favor a dovish, cooperative approach, this increases collaborative tactics and negotiation outcomes (Aaldering and Ten Velden 2018), but can also backfire if representatives concede too much (Steinel et al. 2009).

Integrating research in the domain of representative negotiations with research on motivational orientation in negotiations, we suggest that the influence of constituency voices on negotiation tactics and agreements depends on features of the negotiation setting (distributive or integrative task) and on the dynamic between representatives and their constituencies: the (a)symmetry in constituency composition between negotiating representatives. We also explore the role of potential future interactions and accountability.

This manuscript contributes to literature on negotiations in five ways. First, we explore the impact of hawkish and dovish constituency voices in both distributive and integrative negotiations. Second, we investigate how constituency voices differentially impact representatives' negotiation behavior depending on whether the opponents' constituency is similar to (doves vs doves; hawks vs hawks) or different from (doves vs hawks) one's own. Third, we aim to replicate previous findings that representatives with exclusively dovish constituency members obtain higher outcomes than those with a hawkish constituency in integrative negotiations (Aaldering and Ten Velden 2018). Fourth, we empirically test whether the expectation of future negotiation interaction with the same counterpart may increase cooperation and reduce the competitive influence of hawkish constituency voices on negotiation outcomes. Fifth, and finally, we test whether accountability pressures, even when implicit, increase competitiveness among representatives, regardless of the nature of their constituency.

\subsection{Negotiation Behavior Depends on the Task Setting and Motivational Orientation}

There are two complementary strategies to reach high outcomes in a negotiation (Pruitt and Lewis 1975; De Dreu et al. 2007): Claiming value (a distributive strategy focused on dividing resources and eliciting concessions from the other party) and 
creating value (an integrative strategy focused on collaboratively identifying common interests and finding trade-offs that are beneficial for both parties). The simultaneity of value creation and value claiming (Kopelman 2014) enables optimal individual and joint outcomes. However, value creation is counterintuitive. Negotiators fall prey to a fixed-pie bias (Thompson and Hastie 1990) and assume only competitive tactics will ensure higher gains (Bazerman et al. 2000; Lax and Sebenius 1986), thereby missing opportunities to gain value in integrative settings. In purely distributive settings, the only way to gain value is to claim it, for example, by setting high demands and through a reluctance to make concessions (Siegel and Fouraker 1960; White and Neale 1991, 1994, for a review see Hüffmeier et al. 2014).

Value creation and value claiming strategies, which play out differently in distributive and integrative negotiation settings, are adopted not only based on the structure of the task. The choice of strategy also depends on the motivational orientation of negotiators; a preference for a particular distribution of resources between oneself and the counterpart (McClintock 1977; Rubin and Brown 1975). Generally, individuals can be classified as pro-self (mainly valuing high outcomes for oneself) or as pro-social (valuing high outcomes for both oneself and others). This classification is somewhat artificial, and indeed, social motives can rather be seen as a continuum (Murphy et al. 2011). However pro-self and pro-social motives have been used abundantly to classify, as well as induce, motivational orientations in negotiation research (e.g., Weingart et al. 1993; De Dreu et al., 2000). In integrative negotiations, which allow for both value claiming and value creating strategies, pro-socially motivated negotiators generally reach higher joint outcomes than negotiators with a pro-self motivation, but only when they resist concession making (De Dreu et al. 2000; Tzafrir et al. 2012). When a pro-social negotiator faces a pro-self counterpart, joint outcomes are generally low; the integrative task is approached in a distributive manner, leading to lower than optimal outcomes for both parties and to higher outcomes for the pro-self party (Schei and Rognes 2003; Olekalns et al. 1996a, b).

Thus, strategies to achieve higher outcomes are informed both by the motivation of each party and by the structure of the negotiation setting. Motivational orientation can be derived from stable individual differences in social value orientation (Messick and McClintock 1968), however, it can also be induced with specific goal instructions (e.g., Weingart et al. 1993) or by the accountability pressure of representing a constituency (Ben-Yoav and Pruitt 1984a).

\subsection{Hawkish and Dovish Constituency Influence: Symmetrical and Asymmetrical Constituencies}

Broadly, the presence of a constituency induces a competitive motivational orientation in representatives. It raises feelings of accountability; negotiators need to be able to justify the agreement to their constituency and resist yielding to the other parties' wishes (Druckman 1994; Ben-Yoav and Pruitt 1984a). Such resistance to yielding could be efficient in creating value in integrative negotiations, but only if combined with a cooperative motivational orientation (De Dreu et al. 2000). The nature of constituencies' preferences can form another source of motivation, in 
addition to the competitive motivation caused by the representational role, to guide negotiators' behavior.

Hawkish (competitive) versus dovish (conciliatory) constituency voices have differential effects on representatives' negotiation behavior and outcomes. Generally, even when in the minority, hawkish constituency voices increase competitive or value-claiming negotiation behavior of representatives (Steinel et al. 2009; Aaldering and Ten Velden 2018). Importantly however, the research on the role of hawkish and dovish constituencies, hitherto, either investigated the effect of constituency voices on behavior of one independent party (without actual interaction with a counterpart, Steinel et al. 2009) or assumed symmetric constituencies between representatives (both representatives represented a constituency with the same number of hawkish and dovish voices; Aaldering and De Dreu 2012; Aaldering and Ten Velden 2018). More insight into asymmetric constituencies between negotiating representatives (one represents a hawkish constituency, whereas the other represents a dovish constituency) is crucial to understand how constituency composition impacts outcomes. We explore negotiation outcomes for asymmetrical and symmetrical constituencies in the context of both distributive and integrative negotiation tasks.

In distributive negotiations, drawing on the well-established work that a hardline strategy will pay off in terms of outcomes only if the other party will concede (Hüffmeier et al. 2014; Olekalns et al. 1996a, b), we expect among asymmetric constituencies that hawkish representatives will secure more value than their conciliatory dovish counterparts. The representative with the dovish mandate could be more likely to compromise by making concessions, allowing the larger share of the pie for the party with the hawkish constituency. However, when faced with a (symmetric) hawkish counterpart, representatives of hawkish constituencies likely reciprocate competitive strategies and reluctance to make concessions. Such a competitive cycle could disrupt the negotiation process to the extent that no agreement is reached at all. Indeed, negotiators with a pro-self social motive are more likely to reach impasses in negotiations than pro-socially motivated individuals (Schweinsberg et al. 2012; Trötschel et al. 2011).

Thus, we predict different patterns of negotiation results depending on the symmetric (dovish negotiating with dovish; hawkish with hawkish) versus asymmetric (dovish negotiating with hawkish) structure of constituencies, such that:

Hypothesis 1 In a distributive negotiation with a symmetric structure of constituencies, negotiating pairs of representatives with hawkish constituencies will reach more impasses than negotiating pairs of representatives with dovish constituencies.

Hypothesis 2 In a distributive negotiation with an asymmetric structure of constituencies, representatives of hawkish constituencies will reach higher outcomes than their counterpart with a dovish constituency.

In contrast, when the negotiation has an integrative structure, the constituency dynamics may play out in a different way, such that it could pay off to have a dovish constituency. Although a mere cooperative orientation may induce quick concession 
making (De Dreu and Van Lange 1995), we argue that dovish constituencies encourages a combination of value creation with resistance to yielding that could be advantageous in integrative settings. The mere presence of a constituency induces feelings of accountability, raising resistance to yielding among representatives (Ben-Yoav and Pruitt 1984a), such that the dovish orientation of the constituency may enable the representative to balance both value claiming and the pursuit of creative solutions, thereby leading to high joint outcomes, when the counterpart has a similar (symmetric) constituency. Representatives of hawkish constituencies would likely reciprocate a competitive approach to their (symmetric) hawkish counterpart, and such pursuit of merely value claiming strategies would fail in realizing the integrative potential of the negotiation. Indeed, previous research shows that representatives with dovish constituencies discover more integrative potential and reach fewer impasses than hawkish representatives facing each other (Aaldering and Ten Velden 2018). Replicating and extending this work, we therefore predict that:

Hypothesis 3a In integrative negotiations, representatives of hawkish constituencies will reach lower outcomes than representatives of dovish constituencies when facing a counterpart with the same constituency.

Hypothesis 3b In integrative negotiations, representatives of hawkish constituencies will reach more impasses than representatives of dovish constituencies when facing a counterpart with the same constituency.

The outcomes in integrative negotiations could look very different when the constituencies are asymmetric. On the one hand, representatives with a dovish constituency may end up with less value than their hawkish counterpart, because they make less competitive demands, as well as because they may provide information that weakens their position without reciprocation from their hawkish counterpart. This line of reasoning is supported by research on groups, where pro-self-oriented members secure higher value for themselves than pro-socially oriented members (Schei and Rognes 2005) and findings that pro-self individuals reach higher negotiation outcomes when faced with a pro-socially oriented counterpart (Chen et al. 2003). Following this logic, representatives with a hawkish constituency will claim more value than their compromising dovish counterparts, leading to higher individual outcomes.

On the other hand, there is evidence that pro-social individuals who face a proself counterpart match competitive behavior (Rhoades and Carnevale 1999; Schei and Rognes 2003) adopting a tit-for-tat approach both in prisoner dilemma games and negotiations (e.g., triangle hypothesis, Kelley and Stahelski 1970; for a review of tit-for-tat, see Kopelman 2020). Additionally, pro-social individuals reach higher outcomes when they face a pro-self counterpart (Olekalns et al. 1996a, b). Thus, representatives with a dovish mandate may be less likely to unilaterally concede-a dynamic further fueled by their representational role obligation-while being open to collaborative opportunities that increase gains, thus being simultaneously competitive and cooperative (Kopelman 2014). Following this logic and past findings, 
in asymmetric settings, a dovish representative may realize more of the integrative negotiation potential than the hawkish counterpart.

Given these competing theoretical perspectives and predictions, we approach the question of whether, in integrative settings, representatives with a dovish constituency will reach lower or higher outcomes than their counterpart with a hawkish constituency, through an exploratory analysis.

\subsection{Mitigating Hawkish Influence: The Role of Expected Future Interaction}

Given the potentially detrimental impact of the mere presence of a constituency, and the influence of a hawkish constituency on lower quality negotiation agreements (Aaldering and De Dreu 2012; Druckman 1977), it is important to consider psychological factors that may mitigate competitive dynamics in representative negotiations. We suggest that one such factor is the expectation of a future interaction, a situational feature inducing a pro-social motivation (Ben-Yoav and Pruitt 1984b; Schei and Rognes 2005).

Most negotiations do not take place in isolation. Whether in diplomatic or labor/ business settings, negotiators may meet one another again. The prospect of negotiating with the same party reduces exploitation, which could backfire in a subsequent negotiation (Marlowe et al. 1966), promotes friendliness and cooperation (Shaffer and Ogden 1986), softer influence tactics (Van Knippenberg and Steensma 2003) and more satisfaction with the negotiation (Patton and Balakrishnan 2010). Moreover, it increases concern for the interests of the other party, a problem-solving approach, and the realization of higher joint outcomes in an integrative task (BenYoav and Pruitt 1984b). A future-oriented perspective in a given negotiation allows for another dimension of integrative potential: concessions in the current negotiation can potentially be compensated in the next negotiation. Such thinking may enhance a focus on integrative potential, as well as elicit a collaborative and cooperative negotiation style in the current negotiation. In a distributive task, the expectation of future interaction may increase concession making as a friendly gesture to build towards a positive relationship (Hüffmeier et al. 2014).

However, a future-oriented perspective may impact negotiation behavior differently depending on the constituents' approach. Representatives with a hawkish constituency, even if they are motivated by self-interest, may realize that the way to further their own interests is no longer to demand concessions without reciprocating. Some concession making, even when strategic, could open the door to trade-offs and realizing integrative potential. This would translate into higher outcomes in an integrative task, and fewer impasses in a distributive task. Representatives with a dovish constituency would be less influenced by the expectation of future interaction, as they adopt a collaborative approach even if a future interaction is not salient. The expectation of future interaction may reduce their resistance to yielding, thereby inviting more concessions and lower outcomes both in distributive (less value claiming) and integrative (less value claiming, as well as more focus on unilateral concessions rather than value creation) tasks. These effects are anticipated regardless of the nature of the counterparts' constituency. We thus predict that: 
Hypothesis 4 In both symmetric and asymmetric settings, expectation of future interaction will increase outcomes of representatives with a hawkish, but not of representatives with a dovish constituency.

\section{Overview of Studies}

Four experiments (two interactive dyadic experiments and two individual online scenario experiments) were designed to test our hypotheses. In the first two experiments, representatives negotiated twice, once in a distributive task and once in an integrative task, each with the same counterpart. Only half of the participants received the information that they would perform two negotiation tasks with the same counterpart. In Experiment 1, all representatives had symmetrical constituencies (either both hawkish or both dovish). In Experiment 2, all representatives had asymmetrical constituencies (their counterpart had a constituency different to their own). Experiment 3 was designed to further investigate the role of future interaction and focused on the representative and their first offer, based only on their own constituency. Experiment 4, was designed to explore whether implicit accountability is perceived as high by representatives and whether explicitly lowering accountability pressures reduces competitiveness.

\section{Experiment 1}

Our first experiment was designed to investigate how representatives with symmetrical (hawkish or dovish) constituencies perform in an integrative as compared to a distributive negotiation task ( $\mathrm{H} 1$ and $\mathrm{H} 3)$. Additionally, Experiment 1 considered the role of expected future interaction in the negotiation $(\mathrm{H} 4)$.

\section{Method}

\subsection{Participants and Design}

One hundred eighty-six participants, mainly undergraduate students from a Western European University (Mean age $=23.10, S D=4.45 ; 72.6 \%$ female) participated in exchange for course credit or $€ 10$. Dyads $(N=93)$ based on entrance order of participants were randomly assigned to the 2 (constituency composition: hawkish or dovish $) \times 2$ (expected future interaction [EFI] or not) design. All participants performed two different negotiation tasks: One distributive task and one integrative task. The order in which the negotiation tasks were presented was counterbalanced and controlled for in the analyses. Within each dyad, one participant had the role of union representative, and the other the role of management representative. 
Table 1 The messages used in Experiment 1 and 2, in bold the ones chosen by the alleged constituencies

\begin{tabular}{ll}
\hline Dovish messages & Hawkish messages \\
\hline $\begin{array}{l}\text { Try to get a fair deal. It doesn't have to be free } \\
\text { Don't be too hard, that will benefit us most }\end{array}$ & $\begin{array}{c}\text { Try to get a good deal. The less we pay the better } \\
\text { Don't be too soft, that will benefit us the most } \\
\text { Not all issues are equally important, we can give in } \\
\text { on some issues }\end{array}$ \\
$\begin{array}{ll}\text { Won't negotiate too tough, otherwise we'll regret } \\
\text { it later }\end{array}$ & $\begin{array}{c}\text { Negotiate tough, otherwise we pay more than } \\
\text { necessary }\end{array}$ \\
$\begin{array}{l}\text { Don't be too tough in the negotiations, that will } \\
\text { benefit us more }\end{array}$ & $\begin{array}{c}\text { Don't be too soft in the negotiations, that will } \\
\text { benefit us most }\end{array}$ \\
$\begin{array}{l}\text { It is ok to make concessions, the other party } \\
\text { should benefit too }\end{array}$ & $\begin{array}{c}\text { Don't make concessions, we have to stand our } \\
\text { ground }\end{array}$ \\
\hline
\end{tabular}

\subsection{Procedure and Constituency Manipulation}

Participants were seated behind individual computers and learned that they would represent the union or the management of a large organization in negotiations over a new collective employment contract and received instructions about the negotiation task (see below). Depending on the experimental condition, they were told that there would be two negotiations with the same party, or not. To motivate them to consider their constituencies' wishes and highlight their accountability, they could win a bonus of 30 Euros if their constituency would approve of the agreement.

Participants were told that the constituency consisted of four individuals who allegedly took part in another version of this experiment where they could choose from ten messages to send to their representative (five hawkish and five dovish ones, adapted from Steinel et al. 2009 and Aaldering and De Dreu 2012). Participants read these messages, three of which were presumably chosen and presented in red. Depending on the constituency composition conditions, these three were either dovish or hawkish in nature (see Table 1). Within dyads, constituencies were equal; both members of a dyad received the same hawkish or dovish messages from their constituency. Participants negotiated for $25 \mathrm{~min}$ via a chat program. After the first negotiation, based on condition, participants were either told for the first time, or reminded, that there would be another negotiation with the same party. Instructions for this second negotiation closely resembled the first. After viewing the messages from their constituency again, participants were given twenty minutes for this second negotiation. Subsequently, they submitted their agreements, answered additional questions (see below), were compensated, debriefed, and thanked for participation.

\subsection{Negotiation Task and Dependent Variables}

The negotiation tasks each consisted of five issues regarding a new contract: Salary, the starting date of the new contract, the duration of the contract, salary increase and health insurance coverage by the organization (see Aaldering and Ten Velden 2018, adapted from De Dreu et al. 2006). The issues were represented in a point schedule (Table 2). 
Table 2 Point schedule for union and management representative for the integrative task in Experiment 1 and Experiment 2

\begin{tabular}{|c|c|c|c|c|}
\hline Salary & Start contract & Duration contract & Salary increase & Health Coverage \\
\hline \multicolumn{5}{|c|}{ Point schedule management representative } \\
\hline$€ 15,000(540)$ & 14 weeks (90) & 0,5 year $(180)$ & $0.5 \%(360)$ & $5 \%(120)$ \\
\hline$€ 20,000(450)$ & 12 weeks (75) & 1,0 year $(135)$ & $1 \%(300)$ & $10 \%(90)$ \\
\hline$€ 25,000(360)$ & 10 weeks (60) & 1,5 years $(90)$ & $1.5 \%(240)$ & $15 \%(60)$ \\
\hline$€ 30,000(270)$ & 8 weeks (45) & 2,0 years $(45)$ & $2 \%(180)$ & $20 \%(30)$ \\
\hline$€ 35,000(180)$ & 6 weeks (30) & 2,5 years $(00)$ & $2.5 \%(120)$ & $25 \%(00)$ \\
\hline$€ 40,000(90)$ & 4 weeks (15) & & $3 \%(60)$ & \\
\hline$€ 45,000(00)$ & 2 weeks $(00)$ & & $3.5 \%(00)$ & \\
\hline \multicolumn{5}{|c|}{ Point schedule union representative } \\
\hline$€ 15,000(00)$ & 14 weeks $(00)$ & 0,5 year $(00)$ & $0.5 \%(00)$ & $5 \%(00)$ \\
\hline$€ 20,000(90)$ & 12 weeks (60) & 1,0 year $(30)$ & $1 \%(15)$ & $10 \%(45)$ \\
\hline$€ 25,000(180)$ & 10 weeks (120) & 1,5 years $(60)$ & $1.5 \%(30)$ & $15 \%(90)$ \\
\hline$€ 30,000(270)$ & 8 weeks (180) & 2,0 years $(90)$ & $2 \%(45)$ & $20 \%(135)$ \\
\hline$€ 35,000(360)$ & 6 weeks (240) & 2,5 years $(120)$ & $2.5 \%(60)$ & $25 \%(180)$ \\
\hline$€ 40,000(450)$ & 4 weeks (300) & & $3 \%(75)$ & \\
\hline$€ 45,000(540)$ & 2 weeks (360) & & $3.5 \%(90)$ & \\
\hline
\end{tabular}

Depending on the nature of the task (distributive or integrative), potential points to be gained on each of the issues differed. In the integrative task, only the first issue was distributive, and by making trade-offs on the other issues, parties could receive the maximum joint outcome. A fully integrative solution (810 points for each party) would consist of the following agreement: Salary $€ 30.000$; Start date two weeks, duration 0.5 year, salary increase $0.5 \%$ and health insurance coverage $25 \%$. Alternatively, a compromise agreement on all issues would result in 645 points for each party. The maximum outcome for each party, assuming that the other would give in completely, was 1290.

For the distributive task, the point schedules of the representatives were each other's mirror image (Table 3). On each issue, each representative could gain a maximum of 224 points. This number was chosen to resemble the integrative task as closely as possible; a compromise agreement in all issues would in this task too result in 645 points for each party.

The main dependent variable (individual outcomes) was the individual points gained by one party in the agreement in each task.

The manipulation of constituency composition included six questions (adapted from Aaldering and De Dreu 2012, e.g., 'my constituency wanted me to... 'be accommodating', 'be competitive (reverse coded)', 'make concessions', 'be cooperative', 'place strong demands (reverse coded)', 'negotiate tough'(reverse coded)); a higher score indicated a more dovish constituency (Cronbach's $\alpha=0.97$ and 0.96 for management and union representatives respectively). Answering ranged from 1 (fully disagree) to 7 (fully agree). 
Table 3 Point schedule for union and management representative for the distributive task in Experiment 1 and 2

\begin{tabular}{|c|c|c|c|c|}
\hline Salary & Start contract & Duration contract & Salary increase & Health coverage \\
\hline \multicolumn{5}{|c|}{ Point schedule management representative } \\
\hline$€ 15,000(224)$ & 14 weeks (224) & 0,5 year $(224)$ & $0.5 \%(224)$ & $0 \%(224)$ \\
\hline$€ 20,000(192)$ & 12 weeks (192) & 1,0 year $(192)$ & $1 \%(192)$ & $5 \%(192)$ \\
\hline$€ 25,000(160)$ & 10 weeks (160) & 1,5 years $(160)$ & $1.5 \%(160)$ & $10 \%(160)$ \\
\hline$€ 30,000(129)$ & 8 weeks (129) & 2,0 years $(129)$ & $2 \%(129)$ & $15 \%(129)$ \\
\hline$€ 35,000(86)$ & 6 weeks (86) & 2,5 years $(86)$ & $2.5 \%(86)$ & $20 \%(86)$ \\
\hline$€ 40,000(43)$ & 4 weeks (43) & 3 years $(43)$ & $3 \%(43)$ & $25 \%(43)$ \\
\hline$€ 45,000(00)$ & 2 weeks $(00)$ & 3,5 years $(00)$ & $3.5 \%(00)$ & $30 \%(00)$ \\
\hline \multicolumn{5}{|c|}{ Point schedule union representative } \\
\hline$€ 15,000(00)$ & 14 weeks $(00)$ & 0,5 years $(00)$ & $0.5 \%(00)$ & $0 \%(00)$ \\
\hline$€ 20,000$ & 12 weeks (43) & 1,0 years $(43)$ & $1 \%(43)$ & $5 \%(43)$ \\
\hline$€ 25,000(86)$ & 10 weeks (86) & 1,5 years $(86)$ & $1.5 \%(86)$ & $10 \%(86)$ \\
\hline$€ 30,000(129)$ & 8 weeks (129) & 2,0 years $(129)$ & $2 \%(129)$ & $15 \%(129)$ \\
\hline$€ 35,000(160)$ & 6 weeks (160) & 2,5 years $(160)$ & $2.5 \%(160)$ & $20 \%(160)$ \\
\hline$€ 40,000(192)$ & 4 weeks (192) & 3 years (192) & $3 \%(192)$ & $25 \%(192)$ \\
\hline$€ 45,000(224)$ & 2 weeks (224) & 3,5 years $(224)$ & $3.5 \%(224)$ & $30 \%(224)$ \\
\hline
\end{tabular}

The manipulation of expected future interaction included three items (e.g., 'After the first negotiation, I expected a second negotiation'; ranging from 1 (fully disagree) to 7 (fully agree); Cronbach's $\alpha=0.83$ and 0.82 for management and union representatives, respectively). We also measured satisfaction with the negotiation outcome with five items, e.g. 'I am satisfied with the outcome of the negotiation task', 'I think I reached a good deal in the negotiation', Cronbach's alpha $=0.95$ and 0.94 on the first task and 0.96 and 0.93 on the second task for respectively management and union representatives). ${ }^{1}$

\section{Results}

\subsection{Data Treatment}

Our analyses used outcomes of each party as within subjects factor in a repeated measure design, taking into account non-independence of data within dyads (c.f. Kenny et al. 2006; Trötschel et al. 2015; Majer et al. 2020).

\footnotetext{
${ }^{1}$ The perceived order of the task was also measured with two items asking participants whether they performed the task where they could get 224 points on each issue first and whether they performed the task where they could get different points for each issue first on a 1 (fully disagree) - 7 (fully agree) Likert scale. Participants correctly recalled which task they did first (All $F$-values $>72$, all $p$-values $<.001$ in both Experiment 1 and 2).
} 
The lowest dyadic (joint) outcome on the integrative task was 990. Half of this outcome (495) was assigned to each of the representatives within a dyad that failed to reach an agreement, to be able to retain them in the analyses. We chose to give equal values to each role, rather than impute the lowest individual outcomes for each party, because a) when one party has low outcomes, the other might have high outcomes, which does not necessarily reflect a low quality agreement as an impasse should and b) we did not want to artificially induce role differences (for a similar treatment of impasses, see Carnevale and Lawler 1986; De Dreu et al. 2006; Lewis and Fry 1977; Ten Velden et al. 2010).

\subsection{Manipulation Check}

A 2 (constituency composition) X 2 (perceived cooperativeness by management vs. union representatives) Repeated Measures ANOVA with the last factor within subjects, showed that perceived constituency cooperativeness was higher in the dovish $(M=5.74, S D=0.79$ for management and $M=5.78, S D=0.83$ for union) than in the hawkish condition $(M=1.66, S D=0.70$ for management and $M=1.78, S D=0.75$ for union), $F(1,91)=1066.85, p<0.001, \eta_{\mathrm{p}}{ }^{2}=0.92$, supporting the manipulation of constituency composition.

A 2 (EFI: yes or no) X 2 (expectation of future interaction by management vs. union representatives) Repeated Measures ANOVA with the last factor within subjects supported the manipulation of expected future interaction (EFI) $\left(M_{\mathrm{EFI}}=4.86\right.$, $S D=1.79$ for management, $M_{\mathrm{EFI}}=5.34, S D=1.62$ for union vs. $M_{\mathrm{No}} \mathrm{EFI}=4.19$, $S D=1.89$ for management, $M_{\mathrm{No}} \mathrm{EFI}=3.81, S D=1.85$ for union, $F[1,91]=17.04$, $\left.p<0.001, \eta_{\mathrm{p}}^{2}=0.16\right)$.

\subsection{Hypotheses Testing}

A Chi-square analysis showed a non-significant trend suggesting more impasses on the distributive task (marginal, $\left.\chi^{2}=2.77, p=0.096\right)$ for hawkish $(n=17)$ vs. dovish $(n=10)$ constituency dyads. This does not strictly support Hypothesis 1 , but the trend is in the expected direction.

Hypothesis 3 and 4 were tested with a Repeated Measure ANCOVA, with outcomes for each party as repeated measure factor, with constituency composition and expectation of future interaction as independent variables, and controlled for order of the negotiation tasks. Results revealed a main effect of constituency composition $\left(F(1,88)=4.76, p=0.032, \eta_{\mathrm{p}}{ }^{2}=0.05\right)$. Supporting Hypothesis 3a, outcomes on the integrative task were higher for representatives with a dovish $(M=697.98$, $S D=118.48$ for management, $M=647.87, S D=125.80$ for union) vs. a hawkish ( $M=666.20, S D=158.76$ for management, $M=601.96, S D=153.48$ for union $)$ constituency. Outcomes did not differ between management and union representatives, $F(1,88)=1.14, p=0.289, \eta_{\mathrm{p}}{ }^{2}=0.013$. 
Additionally, and supporting Hypothesis 3b, a Chi-squared analysis showed more impasses for hawkish $(n=13)$ vs. dovish $(n=4)$ constituency dyads on the integrative task $\left(\chi^{2}=6.07, p=0.014\right)$.

Hypothesis 4 was not supported: there was no main effect of expected future interaction on the integrative task, $F(1,88)=1.28, p=0.262, \eta_{\mathrm{p}}{ }^{2}=0.014$ and there was no interaction between constituency composition and expected future interaction, $\left.F(1,88)=1.19, p=0.279, \eta_{\mathrm{p}}{ }^{2}=0.01\right)$. The covariate task order did not affect outcomes on the integrative task, $\left.F(1,88)=0.823, p=0.367, \eta_{\mathrm{p}}{ }^{2}=0.01\right)$.

\section{Experiment 2}

Results of the first experiment largely supported our hypotheses. Although the effect was on the border of significance, pairs of representatives with dovish constituencies achieved higher outcomes than pairs of hawkish representatives on an integrative negotiation task. This replicates previous work (Aaldering and Ten Velden 2018), which reinforces our confidence in this effect. Moreover, both distributive and integrative negotiations ended in impasses more frequently for the dyads representing a hawkish versus a dovish constituency.

However, we did not find support for the expectation of future interaction to boost hawkish representatives' negotiation outcomes. This hypothesis (H4) is tested again in Experiment 2. More importantly, in Experiment 2, constituency composition is manipulated within dyads, creating asymmetrical constituencies, such that each negotiation pair consisted of a dovish and a hawkish representative. This enables us to investigate: (a) whether representatives with a hawkish constituency outperform their dovish counterpart in a distributive negotiation (H2); and (b) whether dovish representatives, when faced with a hawkish counterpart, respond in a conciliatory manner and reach lower outcomes, or increase their share of the pie in an integrative negotiation.

\section{Method}

\subsection{Participants and Design}

Two hundred-twenty participants, mainly undergraduate students from a Western European University (Mean age $=22.98, S D=7.09 ; 75.5 \%$ female), took part in the experiment in exchange for course credit or $€ 12.50$. Participants were randomly assigned to a hawkish or dovish constituency and paired into dyads with opposing constituency compositions $(n=110)$, which were randomly assigned to the expectation of future interaction condition (yes or no). Task order (distributive or integrative) and role (union or management representative) were counterbalanced. 


\subsubsection{Procedure and Task}

The procedure and manipulation of the constituency were the same as in Experiment 1. The only exception was that participants now negotiated with a representative who had received other messages from their constituency than they themselves had, a fact of which they were not explicitly made aware. The negotiation tasks and outcome variables were the same as in Experiment 1, as were the manipulation checks of constituency composition (Cronbach's $\alpha=0.97$ and 0.98 for management and union representatives respectively) as well as the manipulation check for expected interaction (Cronbach's $\alpha=0.85$ and 0.84 for management and union representatives respectively). Here too, satisfaction was measured with the same items as in Experiment 1 (Cronbach's $\alpha=0.94$ and 0.95 for the first task and 0.93 and 0.93 for the second task for management and union representatives respectively).

\subsection{Results}

\subsubsection{Data Treatment}

To investigate individual outcomes for each dyad member, we analyzed outcomes for the dovish and hawkish constituency member as within subjects factor in a repeated measures analysis. This takes the interdependence of the data into account by using the degrees of freedom on the dyad level, yet allows for comparisons of within-dyad outcomes (Trötschel et al. 2015; Majer et al. 2020).

Based on the lowest reached outcomes, we assigned the value of 344 to the impasses on the distributive task. Lowest outcomes on the integrative task were 120 (management) and 210 (union). Assigning such low outcomes for the integrative task would heavily skew our data, hence we assigned the same value as in Experiment 1,495 , to the dyad members who did not reach an agreement $(N=14$ on the integrative task, $N=16$ on the distributive task). ${ }^{2}$

\subsubsection{Manipulation Check}

A repeated measures analysis with the manipulation check for perceived cooperativeness by hawkish vs. dovish representatives as within subjects factor showed the expected effect: Representatives experienced their constituency as more cooperative when they were dovish $(M=5.86, S D=0.75)$ vs. hawkish $(M=3.71, S D=2.26)$, Pillai's Trace $F(1,109)=2270.10, p<0.001, \eta_{\mathrm{p}}{ }^{2}=0.95$.

Expected future interaction was also manipulated successfully as shown by a 2 (EFI: yes or no) X 2 (perceived likelihood of future interaction by management vs. union representative) repeated measures analysis with the last as within-subjects factor, $F(1,108)=32.31, p<0.001, \eta_{\mathrm{p}}{ }^{2}=0.23\left(M_{\mathrm{EFI}}=5.50, S D=1.49\right.$ for management

\footnotetext{
2 When removing the impasses from the data altogether, results for the integrative task become somewhat stronger, $F(1,92)=5.44, p=.022, \eta_{\mathrm{p}}{ }^{2}=.056$ and for the distributive task somewhat less strong, $F$ $(1,89)=6.10, p=.015, \eta_{\mathrm{p}}^{2}=.064$.
} 
and $M_{\mathrm{EFI}}=5.71, S D=1.31$ for union vs. $M_{\mathrm{No} \text { EFI }}=4.21, S D=1.94$ for management and $M_{\mathrm{No} \text { EFI }}=4.17, S D=1.97$ for union).

\subsubsection{Hypothesis Testing}

A 2 (EFI vs. no EFI) X 2 (outcomes hawks vs. outcomes doves) repeated measures Ancova with the last factor as within-subjects factor and controlling for task order and role was conducted to test Hypotheses 2 and 4. Supporting Hypothesis 2, higher outcomes were reached on the distributive task when representatives' constituency was hawkish (facing a dovish counterpart, $M=650.52, S D=164.37$ ) than dovish (facing a hawkish counterpart, $M=506.59, S D=138.87$ ), Pillai's Trace $F(1$, 106) $=10.22, p=0.002 . \eta_{\mathrm{p}}^{2}=0.09$.

The outcomes on the integrative negotiation task were similar, with higher outcomes for representatives with a hawkish constituency than for those with a dovish one, $\left(M_{\text {hawkish }}=764.45, S D=161.39\right.$ vs. $\left.M_{\text {dovish }}=576.41, S D=132.59\right)$, Pillai's Trace $\mathrm{F}(1,106)=3.83, p=0.053, \eta_{\mathrm{p}}{ }^{2}=0.035$. This answers the exploratory question we posed about representatives' outcomes in asymmetrical constituencies, showing that representatives with hawkish constituencies reach higher outcomes in integrative negotiations than their dovish counterpart. There were no main effects nor moderations of expected future interaction on outcomes in either task (all $F$ 's $<1.8$, all $p$ 's $>0.17$ ). Thus, Hypothesis 4 is again not supported.

The covariate task order affected outcomes on the distributive task, $F$ (1, $106)=17.63, p<0.001, \eta_{\mathrm{p}}^{2}=0.14$., as well as on the integrative task $F(1$, $106)=4.01, p=0.048, \eta_{\mathrm{p}}{ }^{2}=0.04$, indicating higher outcomes on the second task. There were no role effects on outcomes on either task (all $F$ 's $<1$ ).

\section{Experiment 3}

Results of Experiment 2 demonstrated that the asymmetry in constituencies importantly influences outcomes; when faced with a hawkish counterpart, dovish representatives reach lower outcomes, regardless of the nature of the task. This stands in contrast to the higher outcomes achieved by dovish representatives in symmetrical constituencies (Experiment 1). Again, similar to findings of Experiment 1, there was no indication that expected future interaction played a role in negotiation outcomes. This is noteworthy, given previous research showing expected future interaction to induce a cooperative motivational orientation (Ben-Yoav and Pruitt 1984b; Patton and Balakrishnan 2010; Shaffer and Ogden 1986). Experiment 3 was designed to better understand the effect of expected future interaction in representative negotiations.

Our operationalization of expected future interaction emphasized that another negotiation would take place with the same person soon after the first negotiation. This may have been interpreted as an opportunity for building a relationship as we intended, but could alternatively have been interpreted as a second chance to exploit the other party. While we did not observe an increase in competitive tactics and 
outcomes under expected future interaction, the manipulation may have rested on the exchange relationship between parties, rather than on building a social relationship through increased other-concern.

Increased other-concern (whether measured as unmitigated communal orientation, Amanatullah et al. 2008, or as straightforwardness, DeRue et al. 2009) is associated with increased concession making in negotiations due to higher value of the relationship (Amanatullah et al. 2008). Importantly, research on other-focus and relationships in negotiations has hardly found direct effects on integrative outcomes (Amanatullah et al. 2008; DeRue et al. 2009; Thompson and DeHarpport 1998; Fry et al. 1983; Thompson et al. 1996). In our third experiment, we therefore investigate concession making as response to a first offer from the other party. Moreover, we expect that an increased emphasis on the potential of future relationship building will facilitate cooperative intentions, even when these are driven by a hawkish motive, and positive views of the relationship in general. Because representatives of dovish constituencies are cooperatively inclined by the nature of their perspective (dovish), the effect of a potential future interaction would be stronger among hawkish representatives. We thus further specify the impact of expected future interaction (initially presented broadly as $\mathrm{H} 4$ ) as follows:

Hypothesis 5 Expectation of future interaction will decrease competitive counteroffers and resistance points of representatives with a hawkish, but not of representatives with a dovish constituency.

Moreover, we used a different negotiation context to enable generalization to other settings.

\subsection{Methods}

\subsubsection{Participants and Design}

Two hundred eighty-four UK inhabitants $(73.9 \%$ female, $25.7 \%$ male, Mean age $=34.40, S D=10.96$, ranging between 18 and 65) participated in an online experiment on prolific.co. Data was collected of 304 participants, but twenty were removed before analyses because they failed a simple attention check item. The experiment had a 2 (constituency: hawkish vs. dovish) X 2 (potential of future interaction [PFI]: Yes or no) design. Participants received 0.67 pound sterling (appr. 0.88 USD) for participation, which took on average eight minutes.

\subsubsection{Procedure and Negotiation Task}

Upon indicating informed consent, participants were asked to imagine negotiating as lawyer on behalf of a company with another lawyer about a patent infringement case. They represented a team of four: The R\&D director, two researchers and the CEO. They were told to negotiate about the license fee; a one-issue distributive negotiation ranging from 500.000 to 2.500 .000 , with increasing steps of 250.000, 
Table 4 The messages used in Experiment 3

\begin{tabular}{ll}
\hline Hawkish messages & Dovish messages \\
\hline Don't be too soft, that will benefit us most & $\begin{array}{c}\text { Don't be too tough in the negotiations, that will } \\
\text { benefit us more } \\
\text { Try to get a good deal, but also listen to the other } \\
\text { side }\end{array}$ \\
$\begin{array}{l}\text { Try to get a good deal, focus on our goals } \\
\begin{array}{l}\text { Negotiate tough, otherwise we don't get what we } \\
\text { need }\end{array}\end{array}$ & $\begin{array}{l}\text { Don't negotiate too tough, that may not pay off } \\
\end{array}$ \\
\hline
\end{tabular}

leading to a total of nine possible agreements. Before starting the negotiation, participants read an email which reiterated alleged previous instructions from their client team. These instructions were either hawkish or dovish and are shown in Table 4. Depending on condition, the email ended with the statement 'You all agreed that it is important to succeed in this negotiation' (no consideration of potential future interaction) or additionally 'Successful resolution of this matter will open the door for future business opportunities with the other company' (in the "potential of future interaction" (PFI) condition). Note that this manipulation does not directly induce a pro-social motivation and only differs from the manipulations in Experiment 1 and 2 by raising awareness about the potential benefits of a future relationship. All participants received the first offer from the other party, which was 750.000 dollar, and made their counteroffer. This was the main dependent variable. They additionally were asked to fill out the lowest agreement they would have accepted (resistance point) and then completed questions about their negotiation behavior, their subjective value in the negotiation, and manipulation check items.

\subsubsection{Materials}

Three items assessed whether representatives had considered future business opportunities during the negotiation (e.g. 'During the negotiation, I kept in mind that I could negotiate a profitable agreement with the other party again in the future', Cronbach's $\alpha=0.69$ ). Answering on these items ranged from 1 (strongly disagree) to 7 (strongly agree).

The manipulation check of hawkishness in the constituency was assessed with four items (e.g. 'My constituency had a competitive mindset', Cronbach's $\alpha=0.83$ ) and the manipulation check of consideration of potential future interaction was assessed with three items (e.g. 'My constituency members reminded me that I could explore future business opportunities with the other negotiation party', Cronbach's $\alpha=0.71$ ). All items were answered on a 1-7 Likert scale, ranging from 1 (completely disagree) to 7 (completely agree). We also measured participants' subjective value and their willingness to negotiate with the same party again using the Subjective Value Inventory (Curhan et al. 2006), Cronbach's $\alpha=0.88$. 


\subsection{Results}

\subsubsection{Manipulation Checks}

ANOVAs showed the expected main effects of constituency and consideration of potential future interaction on the manipulation check scales. Representatives reported that their constituency was more hawkish when they had a hawkish $(M=5.35, S D=1.04)$ vs. dovish constituency $(M=3.51, S D=0.89, F[1$, $283]=260.37, p<0.001, \eta_{\mathrm{p}}{ }^{2}=0.48,95 \%$ CI [1.62, 2.07]. Representatives in the PFI condition reported that they were reminded of potential future interactions more $(M=4.70, S D=1.20)$ than representatives in the no-PFI condition $(M=3.41$, $S D=1.27), F(1,283)=88.39, p<0.001, \eta_{\mathrm{p}}{ }^{2}=0.24,95 \%$ CI $[1.02,1.56]$.

\subsubsection{Hypothesis Testing}

A 2 (constituency: hawkish vs. dovish) $\times 2$ (PFI: yes vs. no) MANOVA was run on counteroffer and resistance point. Multivariate effects for Constituency ( $F$ $\left.[2,279]=27.35, p<0.001, \eta_{p}{ }^{2}=0.16\right)$ and potential of future interaction ( $F[2$, $279]=6.18, p=0.002, \eta_{\mathrm{p}}{ }^{2}=0.04$ ) were followed up with ANOVAs. As expected, representatives with hawkish constituencies $(M=6.89, S D=2.05)$ made higher (more competitive) counteroffers than representatives with dovish constituencies $\left(M=5.50, S D=1.65, F(1,280)=41.75, p<0.001, \eta_{\mathrm{p}}{ }^{2}=0.13,95 \%\right.$ CI $[0.97$, $1.82]$. Moreover, higher counteroffers were made without $\left(M_{\mathrm{No} P \mathrm{PF}}=6.58, S D=1.94\right)$ than with $\left(M_{\mathrm{PFI}}=5.82, S D=1.97\right)$ potential future interaction, $F(1,280)=11.81$, $p=0.001, \eta_{\mathrm{p}}{ }^{2}=0.04,95 \%$ CI $[0.32,1.17]$. Finally, there was a trend towards an interaction between constituency composition and PFI $(F[1,280]=3.33, p=0.069$, $\eta_{\mathrm{p}}{ }^{2}=0.01,95 \%$ CI $\left.[0.54,1.73]\right)$. We chose to further analyze this trend, although it was not significant at the $\mathrm{p}<0.05$ value. Simple effects suggested that representatives with hawkish constituencies made higher counteroffers when they did not, versus when they did, consider the potential of future interaction, $F(1,280)=13.93$, $p<0.001, \eta_{\mathrm{p}}{ }^{2}=0.05$. There was no effect of considering future interaction for representatives with dovish constituencies, $F(1,280)=1.29, p=0.26, \eta_{\mathrm{p}}{ }^{2}=0.01$, see Fig. 1. These findings show marginal support for Hypothesis 5. Representatives also had a higher resistance point with a hawkish $(M=4.85, S D=1.44)$ versus dovish constituency $\left(M=3.74, S D=1.15, F(1,280)=51.73, p<0.001, \eta_{\mathrm{p}}{ }^{2}=0.16,95 \% \mathrm{CI}\right.$ $[0.80,1.40]$, and when they were not considering the potential of future interaction $\left(M_{\mathrm{No} P \mathrm{PFI}}=4.54, S D=1.38\right.$ vs. $M_{\mathrm{PFI}}=4.06, S D=1.42, F(1,280)=9.21, p=0.003$, $\eta_{\mathrm{p}}{ }^{2}=0.03,95 \%$ CI $[0.16,0.76]$. There was no interaction. ${ }^{3}$

\footnotetext{
3 Satisfaction with the negotiation was also measured in Experiment 1 and 2. In Experiment 1, dovish representatives reported higher satisfaction than hawkish representatives on both tasks (On the integrative task: $M_{\text {doves }}=5.12, S D=1.54$ for management, $M_{\text {doves }}=4.49, S D=1.71$ for union, $M_{\text {hawks }}=4.11$, $S D=1.48$ for management and $M_{\text {hawks }}=3.91, S D=1.59$ for union, $F[1,88]=14.23, p<.001, \eta_{\mathrm{p}}{ }^{2}=.14$. On the distributive task: $M_{\text {doves }}=5.19, S D=1.38$ for management, $M_{\text {doves }}=5.12, S D=1.16$ for union, $M_{\text {hawks }}=4.00, S D=1.53$ for management, $M_{\text {hawks }}=4.15, S D=1.57$ for union, $F[1,88]=28.10, p<.001$, $\left.\eta_{\mathrm{p}}{ }^{2}=.24\right)$. There were no such effects in Experiment 2.

In Experiment 3, the Subjective Value Inventory (Curhan et al. 2016) was used to assess subjective value with the negotiation. Representatives' subjective value was not influenced by constituency com-
} 


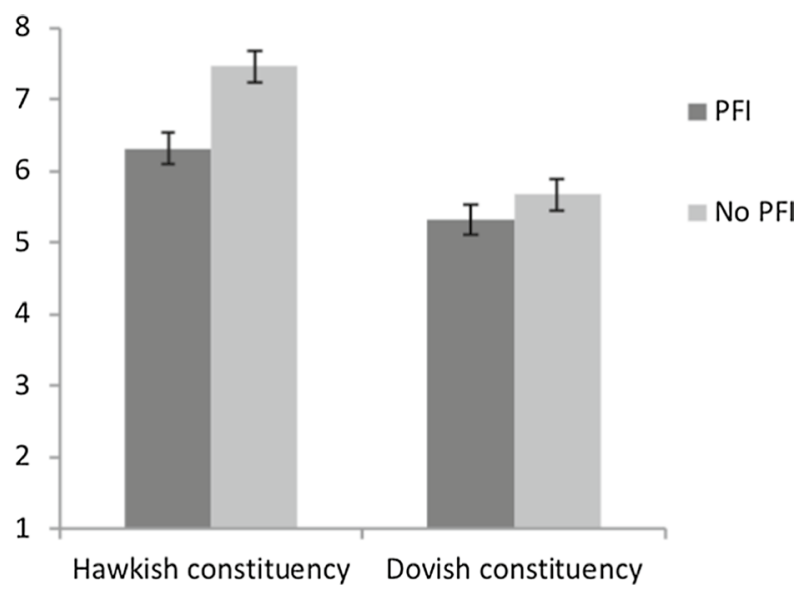

Fig. 1 Counteroffers depending on constituency and potential for future interaction with the same counterpart (Experiment 3)

Thus, results of Experiment 3 provided some, though not conclusive, support for the hypothesized role of the potential of future interaction in decreasing competitive counteroffers by representatives, particularly by representatives with a hawkish constituency. ${ }^{4}$

\section{Experiment 4}

Thus far, our studies have demonstrated the interplay of different combinations of motivational orientation. Representational role induces a competitive orientation, leading to resistance to yielding and higher integrative outcomes when the motivational orientation of the constituency is cooperative (dovish), but not when it is competitive (hawkish) (Experiment 1). Such a double competitive motivational orientation (representative role and hawkish constituents), however, paid off in distributive tasks (Experiment 2), and was somewhat mitigated by the cooperative motivational orientation of expected future interaction (Experiment 3). This reasoning relies on the assumption that the representational role indeed induces a competitive motivation, through the experience of accountability. Accountability was neither explicitly

\footnotetext{
Footnote 3 (continued)

position $(F(1,280)<1, p=.70)$, but was higher when representatives considered the potential of future interaction $(M=4.63, S D=0.68)$ than when they did not $(M=4.38, S D=0.73, F(1,280)=8.68$, $p=.003, \eta_{\mathrm{p}}{ }^{2}=.03$. In Experiment 4 , there were no effects of constituency composition or accountability on subjective value, using the same measure, all $F$ 's $<1$.

4 In Experiment 3, we additionally measured participants' willingness to negotiate with the same person again with one item, and the extent to which they considered future negotiations with the same person with three items. There was a main $\left(F(1,280)=20.90, p<.001, \eta_{\mathrm{p}}{ }^{2}=.07\right)$ and interaction effect $(F(1$, $\left.280)=3.84, p=.051, \eta_{\mathrm{p}}{ }^{2}=.01\right)$ of constituency composition and PFI on consideration of future negotiations, but no effects on willingness to negotiate again.
} 
targeted nor measured in Experiments 1-3. Experiment 1 and 2 included a nonexplicit weak manipulation of accountability given that participants were told they could win extra money by satisfying their constituents. Experiment 3 lacked any reference to accountability.

We designed Experiment 4 to explore to what extent accountability is experienced and influences negotiation behavior, even in the absence of an explicit manipulation. Rather than comparing representatives with non-representatives in their offer making (which has been done before, e.g. Benton and Druckman 1973, 1974; Druckman et al. 1974), we explored manipulations of both explicitly high and low accountability. We compared these with the absence of a manipulation (similar to Experiment 3 ). If the representational role increases accountability — and hence competitiveness, regardless of the orientation of the constituency-we should observe more competitive resistance points when accountability is explicitly high or not mentioned, versus when it is explicitly low. If participants did not experience accountability and its associated competitive orientation, we should observe more competitive resistance points when accountability is high, versus not mentioned and versus explicitly low. We might find a similar effect on counteroffers, although the resistance point is more crucial: It indicates representatives' willingness to concede, while keeping the approval of their constituency in mind.

\subsection{Method}

\subsubsection{Participants and Design}

After removing 32 participants who did not correctly answer the attention check item ('Please indicate 1'), 319 participants completed the study via dataplatform prolific.co (Mean age $=26.81, S D=8.28 ; 45.5 \%$ female, $53.9 \%$ male), in exchange for $£ 0.80$. The sample was diverse in nationalities $28.5 \%$ Polish, $13.8 \%$ Italian, $11.3 \%$ Portuguese, $8.2 \%$ British, 5\% Greek, $4.1 \%$ Spanish and many other countries). They were randomly allocated to one condition of the 2 (constituency: Hawkish vs. dovish) X 3 (accountability: High vs. low vs. control) design.

\subsubsection{Procedure and Task}

The procedure and manipulation of the constituency, as were as the task, were the same as in Experiment 3. The only difference was the manipulation of accountability. In the control condition, there was no mention of accountability, which is similar to the scenario in Experiment 3. To manipulate high accountability, the following sentence was included: 'It is important for you to please your clients. Pleasing your clients today will help your firms' reputation. Also, in addition to compensation you will receive from these clients they will complete a customer satisfaction survey so it is important for you to represent their interests'. For the low accountability condition, this sentence read: 'It is not so important for you to please your clients. Pleasing your clients today will not affect your firms' reputation. Also, it will not impact your compensation and they will not be completing a customer satisfaction survey'. 
This information preceded the manipulation of the dovish vs. hawkish constituency. The high accountability manipulation was repeated before participants were shown the first offer from the other party.

\subsubsection{Materials}

The only difference in materials from Experiment 3 was the addition of three items to check the manipulation of accountability (e.g. 'It was important for me and my firm to negotiate in the interests of my constituency', Cronbach's $\alpha=0.71$ ). All items were answered on a $1-7$ Likert scale, ranging from 1 (completely disagree) to 7 (completely agree).

\subsection{Results}

\subsubsection{Manipulation Checks}

ANOVAs showed the expected main effects of constituency and accountability on the manipulation check scales. Representatives reported that their constituency was more hawkish when they had a hawkish $(M=4.98, S D=1.02)$ vs. dovish constituency $\left(M=3.54, S D=0.88, F[1,313]=185.34, p<0.001, \eta_{\mathrm{p}}{ }^{2}=0.37\right.$. The main effect of accountability was also significant, $F(2,313)=65.58, p<0.001, \eta_{\mathrm{p}}{ }^{2}=0.30$. Accountability was perceived as higher in the high accountability condition than in the control condition $\left(M_{\text {high }}=5.50, S D=0.92, M_{\text {control }}=5.19, S D=0.85\right.$, Contrast Estimate $=-0.32, p=0.034,95 \%$ CI $[-0.62 ;-0.02])$ or the low accountability condition $\left(M_{\text {low }}=3.84, S D=1.46\right.$, Contrast Estimate $=-1.65, p<0.001,95 \%$ CI $[-1.95$; $-1.35]$ ). Accountability was also perceived as higher in the control condition than in the low accountability condition (Contrast Estimate $=-1.33, p<0.001,95 \% \mathrm{CI}$ $[-1.63 ;-1.03])$.

\subsubsection{Exploratory Analysis}

A 2 (constituency: hawkish vs. dovish) $\times 3$ (Accountability: control vs. low vs. high) MANOVA was run on counteroffer and resistance point, revealing multivariate effects for constituency (Roy's largest Root $\mathrm{F}[2,312]=16.66, p<0.001, \eta_{\mathrm{p}}{ }^{2}=0.10$ ) and accountability (Roy's largest Root F [2, 313] $=3.22, p=0.041, \eta_{\mathrm{p}}{ }^{2}=0.02$ ). Follow-up ANOVAs showed that, as expected, representatives with hawkish constituencies $(M=6.48, S D=2.05)$ made higher (more competitive) counteroffers than representatives with dovish constituencies $(M=5.23, S D=1.80, F(1,313)=32.97$, $\left.p<0.001, \eta_{\mathrm{p}}{ }^{2}=0.10\right)$. Accountability did not affect counteroffers, $F(2,313)=0.99$, $p=0.373, \eta_{\mathrm{p}}{ }^{2}=0.006$ and there was no interaction, $F(2,313)=0.34, p=0.71$, $\eta_{\mathrm{p}}{ }^{2}=0.002$.

Additionally, the resistance point of hawkish representatives was higher (more competitive) than that of dovish representatives $\left(M_{\text {hawkish }}=4.41, S D=1.49\right.$, $M_{\text {dovish }}=3.81, S D=1.26, F(1,313)=14.95, p<0.001, \eta_{\mathrm{p}}{ }^{2}=0.05$. Higher accountability also increased the resistance point, $F(1,313)=2.99, p=0.052, \eta_{\mathrm{p}}{ }^{2}=0.02$. 
Contrast analysis showed marginally higher resistance points for high vs. low accountability $\left(M_{\text {high }}=4.19, S D=1.38, \quad M_{\text {low }}=3.85, S D=1.47\right.$, Contrast estimate $=0.34, p=0.074,95 \%$ CI $[-0.72,0.03])$ as well as more competitive (higher) resistance points for the control condition vs. low accountability $\left(M_{\text {control }}=4.31\right.$, $S D=1.39$, Contrast estimate $=-0.45, p=0.020$, 95\%CI $[-0.82,-0.07])$. The high accountability and control condition did not differ (Contrast estimate $=-0.11$, $p=0.58$, 95\% CI $[-0.48,0.27])$. There was no interaction between constituency composition and accountability on the resistance point, $F(1,313)=0.40, p=0.67$, $\eta_{\mathrm{p}}{ }^{2}=0.003$.

\section{General Discussion}

Lay beliefs about negotiations emphasize the value of a competitive approach and forcing concessions. Such beliefs are pervasive among constituency members who are represented in negotiations; whether through election, such as in political negotiations, or appointment, as in labor and organizational negotiations. Given the fixedpie bias (Thompson and Hastie 1990), constituency members frequently assume that the negotiation is zero-sum, and that their representatives should not make concessions to the other party. Accordingly, representing a constituency elicits a competitive negotiation style, especially when the constituency members explicitly express such hawkish preferences. At the same time, research over the past decennia has demonstrated that a collaborative style facilitates optimal agreements. If there is more than one issue being considered (e.g., not only a single-issue such as price), the negotiation task is simultaneously cooperative and competitive in nature (Kopelman 2014) and potentially offers an opportunity to co-create value (for a review see De Dreu et al. 2000). Dovish representatives, who are collaborative and better positioned to create value when facing a similarly dovish constituency representative (Aaldering and Ten Velden 2018), may not experience such an advantage when facing a hawkish representative. The motivational dynamics in these asymmetricrepresentative dyadic negotiations are complex.

Here, we investigated the role of different forms of social motivation in dyadic negotiations: Accountability to constituents, constituency composition, and the role of expected future interaction, in both an integrative and a distributive task. We found that the interplay of social motivations determines negotiation success: Representational accountability combined with a dovish constituency paid off in Experiment 1 , resulting in higher outcomes and fewer impasses on the integrative task. However, when dovish representatives faced a hawkish one (Experiment 2), dovish representatives' outcomes decreased on both integrative and distributive taskspotentially due to too much concession making. Here, the double pro-self motivation of accountability and a hawkish constituency led to higher outcomes. We did not find the expectation of future interaction, a pro-social motivation, to boost outcomes in dyadic negotiations. 


\subsection{Contributions and implications}

The contributions of this research are manifold. We expand and enrich the literature on representative negotiations (De Dreu et al. 2014) and constituency voices and integrate these literatures with literature on motivational orientation in negotiations. Whereas previous research has either investigated integrative (Aaldering and De Dreu 2012; Aaldering and Ten Velden 2018; Ben Yoav and Pruitt 1984a, b) or distributive (Steinel et al. 2009, 2010; Van Kleef et al. 2007) representative negotiations, we directly studied both and thereby exclude the possibility that our findings do not generalize beyond one specific task type. Furthermore, we introduced constituency voices as additional means to induce a pro-social or pro-self motivation in representatives, and demonstrated how representatives respond to their constituencies' voices in their behavior, both in their opening offers (Experiment 3 and 4) and in interactive negotiations (Experiment 1 and 2). We demonstrated that outcomes for representatives reverse, depending on whether the negotiation takes place between representatives with similar-minded (symmetric; Experiment 1) versus different (asymmetric; Experiment 2) constituencies. Representatives with dovish constituencies have the potential to reach the highest quality agreements, but this potential would only be achieved if their counterpart has similar dovish intentions. We introduce consideration of future interaction to mitigate competitive negotiation tactics. While our data is not consistent, we found that the potential of future interaction increases cooperativeness in general, as well as some preliminary support that the potential of future interaction can decrease competitiveness for representatives with hawkish constituencies (Experiment 3). Finally, we showed that accountability plays an important role in representative negotiations; representatives make more competitive offers when accountability is either explicit or implicit, but when accountability is explicitly absent, akin to individual negotiations, competitiveness drops (Experiment 4).

Our findings bear practical implications both for representatives and constituency members in labor relations, diplomacy, and business negotiations. We demonstrate how hawkish preferences can backfire for constituents when their representative faces a similar-minded counterpart. We show how dovish preferences do not invite exploitation due to accountability pressures, yet can lead to the best and most creative agreements-unless the counterpart is hawkish. We also demonstrate how collaborative tactics and higher outcomes can be stimulated for representatives, even when they experience hawkish constituency pressure.

While our findings illuminate important theoretical and empirical dynamics, future research is needed to better understand the dynamics of representative negotiations. For example, while it is interesting and valuable to know how symmetric versus asymmetric constituencies inform negotiation agreements, many other constituency compositions are conceivable. Multi-faceted constituencies in political and organizational negotiation contexts may lead to varying degrees of hawkish and dovish factions in a particular constituency. Additionally, constituencies can differ on facets beyond hawkish- and dovish-ness, such as their similarity to or relationship with the representative, or the degree to which they endorse other types of negotiation strategies (e.g., attitudes towards more or less ethical behavior; Aaldering et al. 
2020), as well as psychological variables, such as culture and emotions (Rees and Kopelman 2019; Druckman and Olekalns 2008). Finally, little is known on whether and when constituency members are willing to accept an agreement that requires different degrees of concession making, and if they would approve of both the negotiated agreement and the representatives (Maoz and McCauley 2005). This unexplored domain will benefit from more research on constituents' perceptions and approval of negotiated agreements.

\section{Concluding remarks}

Constituency pressure leads representatives to adopt a competitive approach in negotiations, leading to suboptimal outcomes. Across four experiments, we demonstrate circumstances under which listening to the hawkish voices can help and harm negotiation outcomes. For representatives and constituency members alike, the potential value of a dovish approach in negotiations can be beneficial in both distributive and integrative settings. Balancing a collaborative approach without weakening one's own position and satisfying the constituency remains a challenge, and a domain important to future research and practice.

Acknowledgements We thank Kayleigh Kops, Ellis Driessen and Jos Boon for their efforts in collecting the data and their contributions to the design of the experiments.

Funding This research was funded by a DRRC Research Residency grant (\# 10024055) from the Kellogg School of Management, Northwestern University, awarded to Dr. Hillie Aaldering and Dr. Shirli Kopelman.

\section{Declarations}

Conflict of interest Each experiment was approved by the ethical review board of the university where the experiment was conducted.

Human and Animal Rights All procedures performed in studies involving human participants were in accordance with the ethical standards of the institutional and/or national research committee and with the 1964 Helsinki declaration and its later amendments or comparable ethical standards.

Informed consent Informed consent was obtained from all individual participants included in the study.

Open Access This article is licensed under a Creative Commons Attribution 4.0 International License, which permits use, sharing, adaptation, distribution and reproduction in any medium or format, as long as you give appropriate credit to the original author(s) and the source, provide a link to the Creative Commons licence, and indicate if changes were made. The images or other third party material in this article are included in the article's Creative Commons licence, unless indicated otherwise in a credit line to the material. If material is not included in the article's Creative Commons licence and your intended use is not permitted by statutory regulation or exceeds the permitted use, you will need to obtain permission directly from the copyright holder. To view a copy of this licence, visit http://creativecommons.org/licen ses/by/4.0/. 


\section{References}

Aaldering H, De Dreu CKW (2012) Why hawks fly higher than doves: intragroup conflict in representative negotiations. Group Process Intergroup Relat 15:713-724. https://doi.org/10.1177/1368430212 441638

Aaldering H, Ten Velden FS (2018) How representatives with a dovish constituency reach higher individual and joint outcomes in integrative negotiations. Group Process Intergroup Relat 22:111-126. https://doi.org/10.1177/1368430216656470

Aaldering H, Zerres A, Steinel W (2020) Constituency norms facilitate unethical negotiation behavior through moral disengagement. Group Decision Negotiation. https://doi.org/10.1007/ s10726-020-09691-1

Amanatullah ET, Morris MW, Curhan JR (2008) Negotiators who give too much: unmitigated communion, relational anxieties, and economic costs in distributive and integrative bargaining. J Pers Soc Psychol 95(3):723. https://doi.org/10.1037/a0012612

Bazerman MH, Curhan JR, Moore DA, Valley KL (2000) Negotiation. Annu Rev Psychol 51(1):279_ 314. https://doi.org/10.1146/annurev.psych.51.1.279

Benton AA, Druckman D (1973) Salient solutions and the bargaining behavior of representatives and non-representatives. Int J Group Tensions 3:28-39

Benton AA, Druckman D (1974) Constituent's bargaining orientation and intergroup negotiations. J Appl Soc Psychol 4(2):141-150. https://doi.org/10.1111/j.1559-1816.1974.tb00664.x

Ben-Yoav O, Pruitt D (1984) Resistance to yielding and the expectation of cooperative future interaction in negotiation. J Exp Soc Psychol 34:323-335. https://doi.org/10.1016/0022-1031(84)90029-5

Carnevale PJD, Lawler EJ (1986) Time pressure and the development of integrative agreements in bilateral negotiations. J Conflict Resolut 30:636-659. https://doi.org/10.1177/0022002786030004003

Chen YR, Mannix EA, Okumura T (2003) The importance of who you meet: Effects of self-versus otherconcerns among negotiators in the United States, the People's Republic of China, and Japan. J Exper Soc Psychol 39:1-15. https://doi.org/10.1016/S0022-1031(02)00514-0

Curhan JR, Elfenbein HA, Xu H (2006) What do people value when they negotiate? Mapping the domain of subjective value in negotiation. J Pers Soc Psychol 91:493-512. https://doi.org/10.1037/00223514.91.3.493

De Dreu CK, Van Lange PA (1995) The impact of social value orientations on negotiator cognition and behavior. Personal Soc Psychol Bullet 21(11):1178-1188. https://doi.org/10.1177/0146167295 2111006

De Dreu CKW, Weingart LR, Kwon S (2000) Influence of social motives on integrative negotiation: a meta-analytic review and test of two theories. J Pers Soc Psychol 78:889-905. https://doi.org/10. 1037/0022-3514.78.5.889

De Dreu CKW, Beersma B, Stroebe K, Euwema MC (2006) The interaction between social motives and epistemic motives in negotiation. J Pers Soc Psychol 90:927-943. https://doi.org/10.1037/00223514.90.6.927

De Dreu CKW, Beersma B, Steinel W, Van Kleef GA (2007) The psychology of negotiation: principles and basic processes. In: Kruglanski AW, Higgins ET (eds) Social psychology: handbook of basic principles. The Guilford Press, pp 608-629

De Dreu CKW, Aaldering H, Saygi O (2014) Conflict and negotiation within and between groups. In: Mikulincer M, Shaver PR, Dovidio JF, Simpson JA (eds) APA handbook of personality and social psychology, Vol. 2: Group processes (APA handbooks in psychology). pp 151-176

DeRue DS, Conlon DE, Moon H, Willaby HW (2009) When is straightforwardness a liability in negotiations? The role of integrative potential and structural power. J Appl Psychol 94(4):1032. https://doi. org/10.1037/a0014965

Druckman D (1977) Boundary role conflict: Negotiation as dual responsiveness. J Conflict Resolut 21:639-662. https://doi.org/10.1177/002200277702100406

Druckman D (1994) Determinants of compromising behavior in negotiation: a meta-analysis. J Conflict Resolut 38(3):507-556. https://doi.org/10.1177/0022002794038003007

Druckman D, Olekalns M (2008) Emotions in negotiation. Group Decis Negot 17:1-11. https://doi.org/ 10.1007/s10726-007-9091-9

Fry WR, Firestone IJ, Williams DL (1983) Negotiation process and out come of stranger dyads and dating couples: do lovers lose? Basic Appl Soc Psychol 4(1):1-16. https://doi.org/10.1207/s15324834b asp0401_1 
Hüffmeier J, Freund PA, Zerres A, Backhaus K, Hertel G (2014) Being tough or being nice? A metaanalysis on the impact of hard-and softline strategies in distributive negotiations. J Manag 40:866892. https://doi.org/10.1177/0149206311423788

Kelley HH, Stahelski AJ (1970) Social interaction basis of cooperators' and competitors' beliefs about others. J Personal Soc Psychol 16(1):66. https://doi.org/10.1037/h0029849

Kenny DA, Kashy DA, Cook WL (2006) Dyadic data analysis. Guilford, New York

Kopelman S (2014) Negotiating genuinely: being yourself in business. Stanford University Press, Stanford California

Kopelman S (2020) Tit for tat and beyond: the legendary work of anatol rapoport. Negot Confl Manage Res 13:60-84. https://doi.org/10.1111/ncmr.12172

Lax DA, Sebenius JK (1986) The manager as negotiator. Free Press, New York

Lewis SA, Fry WR (1977) Effects of visual access and orientation on the discovery of integrative bargaining alternatives. Organ Behav Hum Perform 20:75-92

Majer JM, Trötschel R, Galinsky AD, Loschelder DD (2020) Open to offers, but resisting requests: how the framing of anchors affects motivation and negotiated outcomes. J Pers Soc Psychol 119:582-599

Maoz I, McCauley C (2005) Psychological correlates of support for compromise: a polling study of Jewish-Israeli attitudes toward solutions to the Israeli-Palestinian conflict. Polit Psychol 26:791-808. https://doi.org/10.1111/j.1467-9221.2005.00444.x

Marlowe D, Gergen K, Doob A (1966) Opponents' personality, expectation of social interaction and interpersonal bargaining. J Pers Soc Psychol 3:206-213. https://doi.org/10.1037/h0022898

McClintock C (1977) Social motives in settings of outcome interdependence. In: Druckman D (ed) Negotiations: social psychological perspective. Sage, Beverly Hills, pp 49-77

Messick DM, McClintock CG (1968) Motivational bases of choice in experimental games. J Exp Soc Psychol 4(1):1-25. https://doi.org/10.1016/0022-1031(68)90046-2

Murnighan JK, Babcock L, Thompson L, Pillutla M (1999) The information dilemma in negotiations: effects of experience, incentives, and integrative potential. Int J Conflict Manag 10(4):313-339. https://doi.org/10.1108/eb022828

Murphy RO, Ackermann KA, Handgraaf M (2011) Measuring social value orientation. Judgm Decis Mak 6(8):771-781. https://doi.org/10.2138/ssrn.1804189

Nelissen RMA, Dijker AJ, De Vries NK (2007) How to turn a hawk into a dove and vice versa: interactions between emotions and goals in a give-some dilemma game. J Exp Soc Psychol 43:280-286. https://doi.org/10.1016/j.jesp.2006.01.009

Olekalns M, Smith PL, Kibby R (1996a) Social value orientations and negotiator outcomes. Eur J Soc Psychol 26:299-313. https://doi.org/10.1002/(SICI)1099-0992(199603)26:2\%3c299::AID-EJSP7 $56 \% 3 \mathrm{e} 3.0 . \mathrm{CO} ; 2-\mathrm{H}$

Olekalns M, Smith PL, Walsh T (1996b) The process of negotiating: strategy and timing as predictors of outcomes. Organ Behav Hum Decis Process 68:68-77. https://doi.org/10.1006/obhd.1996.0090

Patton C, Balakrishnan PS (2010) The impact of expectation of future negotiation interaction on bargaining processes and outcomes. J Bus Res 63:809-816. https://doi.org/10.1016/j.jbusres.2009.07.002

Pruitt DG, Lewis SA (1975) Development of integrative solutions in bilateral negotiation. J Pers Soc Psychol 31:621-633. https://doi.org/10.1037/0022-3514.31.4.621

Rees L, Kopelman S (2019) Logics and logistics for future research: appropriately interpreting the emotional landscape of multi-cultural negotiations. Negot Confl Manage Res 12:131-145. https://doi. org/10.1111/ncmr.12152

Rhoades JA, Carnevale PJ (1999) The behavioral context of strategic choice in negotiation: a test of the dual concern model. J Appl Soc Psychol 29:1777-1802. https://doi.org/10.1111/j.1559-1816.1999. tb00152.x

Rubin JZ, Brown BR (1975) The social psychology of bargaining and negotiation. Academic Press, New York

Saygı Ö, Greer LL, van Kleef GA, De Dreu CK (2014) Competitive representative negotiations worsen intergroup relations. Group Process Intergroup Relat 17:143-160. https://doi.org/10.1177/13684 30213507321

Sayg1 Ö, Greer LL, van Kleef GA, De Dreu CK (2015) Bounded benefits of representative cooperativeness in intergroup negotiations. Group Decis Negot 24(6):993-1014. https://doi.org/10.1007/ s10726-014-9426-2

Schei V, Rognes JK (2003) Knowing me, knowing you: own orientation and information about the opponent's orientation in negotiation. Int J Confl Manag 14:43-59. https://doi.org/10.1108/eb022890 
Schei V, Rognes JK (2005) Small group negotiation: when members differ in motivational orientation. Small Group Research 36:289-320. https://doi.org/10.1177/1046496404273145

Schweinsberg M, Ku G, Wang CS, Pillutla MM (2012) Starting high and ending with nothing: the role of anchors and power in negotiations. J Exp Soc Psychol 48:226-231. https://doi.org/10.1016/j.jesp. 2011.07.005

Shaffer DR, Ogden JK (1986) On sex differences in self-disclosure during the acquaintance process: the role of anticipated future interaction. J Pers Soc Psychol 51:92-101. https://doi.org/10.1037/00223514.51.1.92

Siegel S, Fouraker L (1960) Bargaining behavior and group decision making: experiments in bilateral monopoly. McGraw-Hill, New York, p 1960

Steinel W, De Dreu CKW, Ouwehand E, Ramírez-Marín JY (2009) When constituencies speak in multiple tongues: the relative persuasiveness of hawkish minorities in representative negotiation. Organ Behav Hum Decis Process 109:67-78. https://doi.org/10.1016/j.obhdp.2008.12.002

Steinel W, van Kleef GA, van Knippenberg D, Hogg MA, Homan AC, Moffit G (2010) How intragroup dynamics affect behavior in intergroup conflict: the role of group norms, prototypicality, and need to belong. Group Process Intergroup Relat 13:779-794. https://doi.org/10.1177/1368430210375702

Ten Velden FS, Beersma B, De Dreu CKW (2010) It takes one to tango: the effects of dyads' epistemic motivation composition in negotiation. Pers Soc Psychol Bull 36:1454-1466. https://doi.org/10. $1177 / 0146167210383698$

Thompson L, DeHarpport T (1998) Relationships, goal incompatibility, and communal orientation in negotiations. Basic Appl Soc Psychol 20(1):33-44. https://doi.org/10.1207/s15324834basp2001_4

Thompson LL, Hastie R (1990) Social perception in negotiation. Organ Behav Hum Decis Process 47:98-123. https://doi.org/10.1016/0749-5978(90)90048-E

Thompson L, Peterson E, Brodt SE (1996) Team negotiation: an examination of integrative and distributive bargaining. J Pers Soc Psychol 70:66-78. https://doi.org/10.1037/0022-3514.70.1.66

Thompson LL, Wang J, Gunia BC (2010) Negotiation. Annu Rev Psychol 61:491-515. https://doi.org/10. 1145/annurev.psych.093008.100458

Trötschel R, Hüffmeier J, Loschelder DD, Schwartz K, Gollwitzer PM (2011) Perspective taking as a means to overcome motivational barriers in negotiations: when putting oneself into the opponent's shoes helps to walk toward agreements. J Pers Soc Psychol 101:771-790. https://doi.org/10.1037/ a0023801

Trötschel R, Loschelder DD, Höhne BP, Majer JM (2015) Procedural frames in negotiations: how offering my resources versus requesting yours impacts perception, behavior, and outcomes. J Pers Soc Psychol 108:417-435. https://doi.org/10.1037/pspi0000009

Turel O (2010) Interdependence issues in analyzing negotiation data. Group Decis Negot 19:111-125. https://doi.org/10.1007/s10726-008-9118-x

Tzafrir SS, Sanchez RJ, Tirosh-Unger K (2012) Social motives and trust: implications for joint gains in negotiations. Group Decis Negot 21:839-862. https://doi.org/10.1007/s10726-011-9252-8

Van Knippenberg B, Steensma H (2003) Future interaction expectations and the use of soft and hard influence tactics. Appl Psychol 52:55-67. https://doi.org/10.1111/1464-0597.00123

Van Kleef GA, Steinel W, van Knippenberg D, Hogg M, Svensson A (2007) Group member prototypicality and intergroup negotiation: how one's standing in the group affects negotiation behaviour. Br $\mathrm{J}$ Soc Psychol 46:129-154. https://doi.org/10.2139/ssrn.609302

Weingart LR, Bennett RJ, Brett JM (1993) The impact of consideration of issues and motivational orientation on group negotiation process and outcome. J Appl Psychol 78(3):504. https://doi.org/10.1037/ 0021-9010.78.3.504

Weingart LR, Hyder EB, Prietula MJ (1996) Knowledge matters: the effect of tactical descriptions on negotiation behavior and outcome. J Pers Soc Psychol 70(6):1205. https://doi.org/10.1037/00223514.70.6.1205

White SB, Neale MA (1991) Reservation prices, resistance points, and BATNAS: determining the parameters of acceptable negotiated outcomes. Negot J 7:379-388

White SB, Neale MA (1994) The role of negotiator aspirations and settlement expectancies in bargaining outcomes. Organ Behav Hum Decis Process 57:300-317. https://doi.org/10.1006/obhd.1994.1017

Publisher's Note Springer Nature remains neutral with regard to jurisdictional claims in published maps and institutional affiliations. 